\title{
PENGARUH PERMINYAKAN TERHADAP PENGECATAN DASAR
}

\author{
Heru Budi Susanto, Titik Purwati W, Hasan B.
}

\section{ABSTRACT}

The aim of this experiment was to evaluate the effects of the fatliquor agents on the color of this coust. Materials used on this experiment were 30 pieces of hall skin, grade l - II with 0.6 1) $7 \mathrm{~mm}$ in their thickness. Tho types of farliquor agents used in this experiment, there were stuthetic (M/) and nanual fatliquor agents (M2). Each fatliquor agents were appliced to the three basc color (beige, red and blue). The fatliquor agent used were I2"

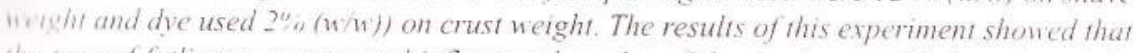
this type of fatliquor agents used influence the color of the died crust. All the colst of the

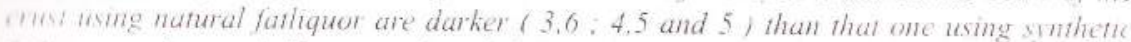
fattrquor and control. However: the rubfastness (dry and wet) of crust using the smithetic fatliquor (4.22 and 4.44) better than that one using natural oil (3.67 and 3.34).

\section{PENDAHULUAN}

Dalam industri pengolahan kulit, ketidak sesuaian warna hasil proses dengan warna permintaan konsumen merupakan masalah yang sangat sering dujumpai. mungkin warna menjadi lebih tua atau lebih muda, baik dari wama cat dasamya maupun warna cat tutupnya. Cara mengatasi ketidak sesuaian warna cat tutup lebih mudah, karena hasil warnanya dapat segera dilihat, akan tetapi untuk warna cat dasar diperlukan waktu yang lebih lama mulai dari proses pembasahan kembali, pengcatannya sendiri, fiksasi sampai pengeringannya.

Proses pengecatan dasar lebih sulit karena warna yang dikehendaki tidak dapat langsung dilihat hasilnya seketika, disamping itu warna yang dihasilkan akan berbeda pada waktu kondisi kulit masih basah dengan warna kulit setelah kering, sehingga tidak mustahil untuk memperoleh satu warna tertentu diperlukan beberapa kali pengulangan.

Pada proes pengolahan kulit biasanya dilakukan proses peminyakan, proses peminyakan antara lain bertujuan untuk melicinkan serat-serat kulit, menjaga agar serat-serat kulit tidak lengket satu dengan lainnya dan memperkecil daya serap kulit terhadap air ataupun cairan lainnya, sehingga kulit lebih tahan terhadap tarikan atau gaya mekanik lainnya, kulit menjadi lebih lunak dan lemas, serta tidak mudah menjadi basah.

Proses peminyakan dapat dilakukan dengan berbagai tahapan, baik sebelum maupun setelah proses pewarnaannya sendiri. Perbedaan jenis minyak yang digunakann menyebabkan terjadinya warna kulit kras yang berbeda, hal ini tentu juga akan menyulitkan dalam proses penyelesaian selanjutnya terutama untuk kulit- 
kulit yang tidak dicat tutup.

Sejalan dengan masalah tersebut duatas, diperlukan penelitian untuk mengetahui sejauh mana pengaruh jenis minyak yang digunakan terhadap warna hasil pengecatan dasar kulit.

\section{MATERI DAN METODE PENELITIAN}

\section{Materi Penelitian.}

Bahan yang digunakan dalam penelitian ini adalah kulit domba khrom basah (wet blue) kualitas I - Il. tebal 0,6-0,7 mm sebanyak 15 lembar dibelah menjadi 30 tengahan lembar.

Khemikalika yang digunakan adalah minyak alami (TRO), minyak sintetis (Sandolix WWL). cat dasar (beige. merah. biru) dan bahan-bahan pembantu lainnya.

Sedangkan mesin/alat yang digunakan anatara lain adalah : mesin serut, drum pengecatan kecil. "grey scale" dan peralatan gelas lainnya.

\section{Metoda Penelitian.}

Untuk mendapatkan formulasi proses pengolahan kulit krom basah (wet blue) sampai dengan kulit kras dicat dasar (dyed crust) yang akan diterapkan pada penelitian terlebih dahulu dilakukan penelitian pendahuluan, menggunakan 3 potong kulit.

Penelitian dilakukan dengan variasi jenis minyak.Penggunaan minyak sintetik dinyatakan dengan kode M1. Penggunaan minyak alami dinyatakan dengan kode M2 dan tanpa perminyakan dinyatakan dengan kode M0.

Dalam penelitian setiap perlakukan menggunakan 3(tiga) kali ulangan. Masing-masing variasi perlakuan tersebut ditetapkan untuk 3 macam warna (biege, merah,biru). Total sampel kulit yang digunakan sebanyak 27 potong kulit.

Prosentase penggunaan minyak dibuat tetap, yaitu sebanyak $12 \%$ dari berat kulit setelah diserut (shaving). Cat dasar yang digunakan sebanyak $2 \%$ dari berat kulit kras.

Gambar 1 : Diagram alir pengolahan kulit krom basah menjadi kulit kras

$200 \%$ air $35^{\circ} \mathrm{C}$

$0.25 \%$ asam formiat

$0.25 \%$ Tergolix A

$200 \%$ air $35^{\circ} \mathrm{C}$

0. $5 \%$ Natrium formiat

1\%, Natrium bikarbonat

$200 \%$ air $35^{\circ} \mathrm{C}$

$200 \%$ air $35^{\circ} \mathrm{C}$

$6 \%$ Bahan

penyamakan ulang

$200 \%$ air $60^{\circ} \mathrm{C}$

$12 \%$ Bahan peminyakan

(sintetik/alami)

$+1 \%$ Asam formiat

$200 \%$ air

$100 \%$ air

$0,2 \%$ Busan $30 \mathrm{~L}$
Putar 25 menit

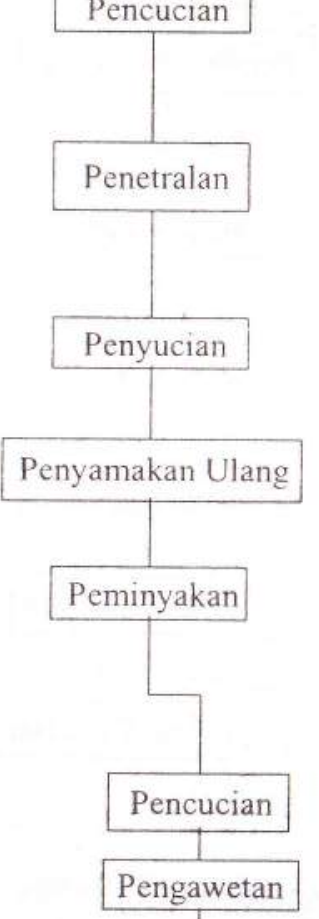

Pencucian

Pengeringan

Kulit Kras
$\mathrm{pH} 5.6$

putar 60 menit

Putar 10 menit

Putar 60 menit

Putar 60 menit

Putar 20 menit pH 3,5 - 3,8

Putar 10 menit

Putar 20 menit

5 menit

kering angin 
Gambar 2 : Diagram alir proses pengecetan dasar kulit kras

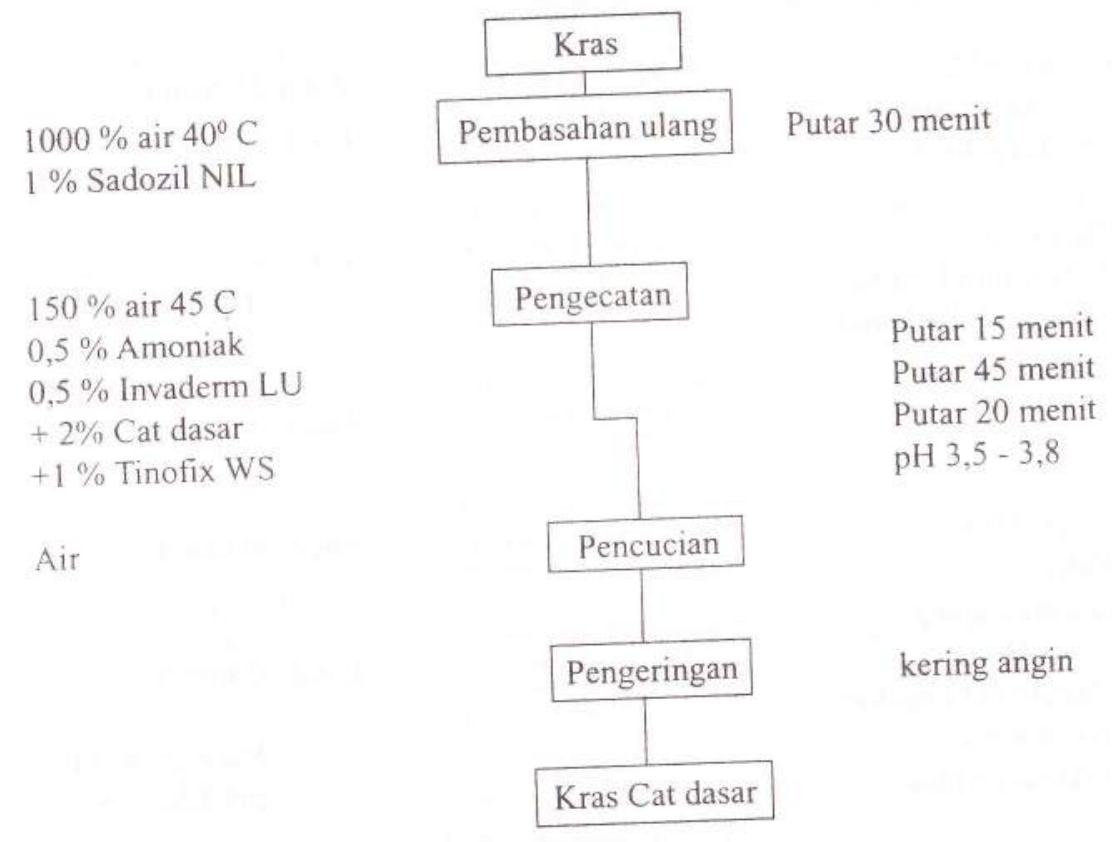

Pengujian

Penguian dilakukan di laboratorium PMNK, Balai Pengembangan Barang kulit, meliputi pengujian warna kulit yang dihasilkan dan pengujian ketahanan gosok basah dan kering.

Warna kulit yang dihasilkan diamati dengan grey scale, sebagai pembanding digunakan warna kulit tanpa peminyakan (Mo).

Ketahanan gosok basah dan kering diuji memakai crok meter, perbedaan (ilakukan 3 kali ulangan.

\section{Analisa Data}

Data yang diperloleh dari hasil pengamatan dianalisa secara statistik menggun test. (Bambang Srigandodno, 1981(

\section{Hasil dan Pembahasan}

Kulit kras hasil penelitian dilakukan pengamatan perbedaan warnanya serta ketahanan gosok basah dan keringnya.

\section{1. pengamatan Warna}

Hasil pengamatan perbedaan warna dengan grey scale pada kulit kras scbelum dan sesudah diberi warna adalah sebagai berikut :

Tabel 1. : Hasil pengamatan perbedaan warna kulit kras tidak dicat dasar.

\begin{tabular}{l|c|c|c}
\multirow{2}{*}{ Perlakuan } & \multicolumn{3}{|c}{ Ulangan } \\
\cline { 2 - 4 } & 1 & 2 & 3 \\
\hline Mo & 5 & 5 & 5 \\
M1 & 4 & 4 & 5 \\
M2 & 3 & 4 & 4 \\
\hline
\end{tabular}

Dari analisa statistik daapat dilihat adanya perbedaan uang sangat nyata antara Mo dengan $\mathrm{M} 1$ dan $\mathrm{M} 2$.

Tabel 2 : Hasil Pengamatan perbedaan warna terhadap kulit kras dicat dasar.

\begin{tabular}{l|lll|lll|lll|}
\hline \multirow{2}{*}{ Perlakuan } & \multicolumn{3}{|c|}{ Warna merah } & \multicolumn{3}{c|}{ Warna biru } & \multicolumn{3}{c}{ Warna biege } \\
\cline { 2 - 10 } & \multicolumn{3}{|c|}{ ulangan } & \multicolumn{3}{c|}{ ulangan } & \multicolumn{3}{c}{ ulangan } \\
\cline { 2 - 10 } & 1 & 2 & 3 & 1 & 2 & 3 & 1 & 2 & 3 \\
\hline$M_{0}$ & 5 & 5 & 5 & 5 & 5 & 5 & 5 & 5 & 5 \\
$M_{1}$ & 4 & 4 & 5 & 4 & 4 & 4 & 4 & 4 & 5 \\
$M_{2}$ & 4 & 4 & 4 & 4 & 4 & 4 & 3 & 3 & 3 \\
\hline
\end{tabular}

Untuk warna merah terdapat beda nyata antara $M_{0}$ dengan $M_{1}$ dan $M_{2}$

Untuk warna biru terdapat beda nyata antara $M_{2}$ dengan $M_{0}$ dan $M_{1}$

Berdasarkan hasil penelitian menunjukkan bahwa setiap variasi perlakuan memberikan warna kulit kras yang berbeda, baik untuk kulit kras yang tidak dicat dasar maupun untuk kulit kras yang dicat dasar.

Kulit kras yang diproses menggunakan minyak alami mempunyai warna yang lebih tua dari pada kulit kras yang menggunakan minyak sintetik, maupun yang tidak diminyaki. Nilai rata-rata Grey Scale kulit kras dengan minyak alami adalah : 3,6 sedangkan dengan minyak sintetik : 4,2. Hal ini senada dengan yang dikatakan oleh Detmar dan Fritz (1990) pemakaian jenis minyak akan mempengaruhi warna kulit kras yang dihasilkan, dikatakan juga bahwa minyak alami mengandung emulsifier, adanya emulsifier akan menghambat masuknya cat kedalam kulit sehingga pada waktu fiksasi sebagian cat tetap terkumpul dipermukaan kulit dan menyebabkan warna kulit semakin tua dan tidak rata. 


\section{Ketahanan gosok}

Tabel 3 : Pengujian ketahanan gosok basah kulit kras dicat dasar

\begin{tabular}{l|lll|lcl|ccc}
\hline \multirow{2}{*}{ Perlakuan } & \multicolumn{3}{c|}{ Warna merah } & \multicolumn{3}{c|}{ Warna biru } & \multicolumn{3}{c}{ Warna biege } \\
\cline { 2 - 10 } & \multicolumn{3}{|c|}{ ulangan } & \multicolumn{3}{c|}{ ulangan } & \multicolumn{3}{c}{ ulangan } \\
\cline { 2 - 10 } & 1 & 2 & 3 & 1 & 2 & 3 & 1 & 2 & 3 \\
\hline$M_{0}$ & 4 & 3 & 3 & 3 & 3 & 4 & 4 & 4 & 4 \\
$M_{1}$ & 3 & 3 & 3 & 3 & 3 & 3 & 3 & 3 & 3 \\
$M_{2}$ & 3 & 3 & 2 & 2 & 2 & 3 & 3 & 2 & 3 \\
\hline
\end{tabular}

Dari analisa statistik diperoleh hasil terdapat beda nyata antara $\mathrm{M}_{0}$ dengan $\mathrm{M}$, dan $\mathrm{M}$, untuk kulit warna beige.

Tabel 4 : Penguiian ketahanan gosok kering kulit kras dicat dasar

\begin{tabular}{|c|c|c|c|c|c|c|c|c|c|}
\hline \multirow{3}{*}{ Perlakuan } & \multirow{2}{*}{\multicolumn{3}{|c|}{$\begin{array}{c}\text { Warna merah } \\
\text { ulangan }\end{array}$}} & \multirow{2}{*}{\multicolumn{3}{|c|}{$\begin{array}{c}\text { Warna biru } \\
\text { ulangan }\end{array}$}} & \multicolumn{3}{|c|}{ Warna biege } \\
\hline & & & & & & & & ng & \\
\hline & 1 & 2 & 3 & 1 & 2 & 3 & 1 & 2 & 3 \\
\hline $\mathrm{M}_{0}$ & 5 & 5 & 5 & 4 & 5 & 5 & 5 & 5 & 5 \\
\hline$M_{1}^{0}$ & 5 & 4 & 5 & 4 & 4 & 4 & 5 & 4 & 5 \\
\hline $\mathrm{M}_{2}$ & 3 & 4 & 3 & 3 & 4 & 3 & 3 & 4 & 4 \\
\hline
\end{tabular}

Untuk warna merah terdapat beda sangat nyata antara $M_{2}$ dengan $M_{0}$ dan

$\mathrm{M}_{1}$

Untuk warna merah terdapat beda nyata antara $M_{0}$ dengan $M_{2}$

Untuk warna biege terdapat beda sangat nyata antara $M_{2}$ dengan $M_{1}$ dan $M_{0}$.

kengujian ketahanan gosok basah dan kering terhadap kulit

Berdasarkan pengujian ketahanation diminyaki mempunyai kras warna merah, biru dan bige, ternyata kulit yang tid yang menggunakan minyak ketahanan gosok paling baik ( 5 dan 4,89 ), disusul kulit yang sintetik $(4,22,44)$ dan yang paling jelek ketah

menggunakan minyak alami (3,67 dan 3,44$)$ leh jenis cat dasar, bahan pembantu Sifat terhadap gosok, dipengaruhi oleh jenis cat dasar, bahan pemar dan Fritz, pengecatan, proses penyamakan ulang dan proses peminyakan.(Din minak sintetik 1990) Untuk kulit kras yang diproses dengan menggunakan mengunakan ketahanan gosoknya lebih baik dari pada kulit kras yang diproses minyak alami minyak alami. Perbedaan tersebut karena minyak alami, khususnya minyak alamin yang disulfatasi bersifat kurang stsbil sehinga dalit dan mengurangi ketahanan kali mengakibatkan cat terakumulasi dipermukaan kulit 1989).

\section{Kesimpulan}

dari hasil penelitian dapat diambil kesimpulan bahwa :

1. Jenis minyak yang digunakan mempengaruhi warna dan ketahanan gosok (basah dan kering) kulit kras yang dihasilkan.

2. Kulit yang diproses menggunakan minyak alami menghasilkan warna yang lebih tua dari pada yang diproses menggunakan minyak sintetik.

3. Kulit yang diproses menggunakan minyak sintetik ketahanan gosoknya lebih baik daripada kulit yang diproses dengan minyak alami.

\section{PUSTAKA}

Bambang Srigandono. (1981), Rancangan Percobaan, Universitas Diponegoro.Semarang, page $65-69$.

Detmer, AH and Frizt,H (1990). Reproducibility of Leather Dyeing. Journal Of American Leather Chemist Assosiation Vol. LXXXV No. 6 page 182 - 188.

0tto. Gerhard (1977). Mechanism of Leather Dyeing. in The Chemistry and Technology of Leather Vol. III (O'flaherty, F., Editor). Krieger Publishing Company, Malabar, Florida; page 17 - 19.

Meiyanti, (Koordinator) (1990). Penganeka Ragaman Warna Kulit Sarung Tangan, Garment dan Tas Wanita. Laporan Penelitian BBKKP, Yogyakarta, page 2 4.

Rao, J.B.,(1979). Vegetable Tanning With Particular Reference to E.I. Tanning, in The Dyeing and Finishing of Leather by Rao, K.C. and M.S. Olivanan. Central Leather Institute, Madras, India. page 68 - 69.

Retzch, E. C., (1977). The Chemistry of Fatliquoring Emulsions, in The Chemistry and Technology of Leather Vol. III (O'flaherty, F., editor). Robert E Kriger Publishing Company, Malabar, Florida, page $61-71$.

Sarkar, K.T., (1980). Theory and Practice of Leather Manufacture. Central Leather Research Institute, Madras India, page 248 - 255.

Shreve, R.M., (1967). Chemical Process Industries, 3rd edition. Mc Graw Hill Kogakusha Ltd, Tokyo.

Venkatakalam.P.S., (1979), Processes and Principles of Dyeing and Finishing, in The Dyeing and Finishing of Leather by Rao, K.C. and M.S. Olivanan. Central Leather Research Institute, Madras India, page 108 - 110.

Wachsmann, M. H., (1989). Fastness Properties of Dyed Leather Influenced by Dye and Substrate (Migration and Perspiration). Journal of American Leather and Chemical Association, Vol.LXXXIV No. 6. page 180 - 183. 